\title{
Recognition and Treatment of Homozygous Familial Hypercholesterolemia by Primary Care Physicians: a Survey from the National Lipid Association
}

\author{
Linda Hemphill, MD, FACC, FNLA ${ }^{7}$, Anne Goldberg, MD, FACP, FNLA ${ }^{2}$, \\ Kees Hovingh, $M D, P h D^{3}$, Jerome Cohen, $M D, F N L A^{4}$, and Dean G. Karalis, MD, FACC, \\ FNLA ${ }^{5}$
}

'Massachusetts General Hospital, Boston, MA, USA; ${ }^{2}$ Washington University School of Medicine, St. Louis, MO, USA; ${ }^{3}$ University of Amsterdam, Amsterdam, NL, USA; ${ }^{4}$ St. Louis University, St. Louis, MO, USA; ${ }^{5}$ Thomas Jefferson University Hospital, Philadelphia, PA, USA.

$\mathrm{J}$ Gen Intern Med 35(7):2225-7

DOI: $10.1007 / \mathrm{s} 11606-019-05620-4$

(c) The Author(s) 2019

\section{INTRODUCTION}

Homozygous familial hypercholesterolemia $(\mathrm{HoFH})$ is an inherited disorder caused most commonly by mutations in the low-density lipoprotein (LDL) receptor gene. The very high levels of LDL-cholesterol from birth lead to early and widespread atherosclerosis, and guidelines recommend early and intensive lowering of LDL-cholesterol. ${ }^{1}$ The prevalence of $\mathrm{HoFH}$ in the general population is more common than previously estimated, with about 1 in 160,000 to 300,000 having HoFH. The National Lipid Association conducted a survey to evaluate how primary care and other clinicians diagnose and manage patients with $\mathrm{HoFH}$. We focused on clinicians in primary care and general medicine since they are usually the first in the healthcare community to see these patients.

\section{METHODS}

A total of 504 clinicians completed the survey across the USA from June to July 2018. The respondents had to be currently treating patients with elevated LDL-cholesterol and licensed to prescribe medications. Eligible medical disciplines included physicians, nurse practitioners, and physician assistants. Eligible specialty groups included family practice, general internal medicine, and cardiology.

\section{RESULTS}

Of those who completed the survey, $85 \%$ were physicians, $99 \%$ were in primary care or general internal medicine, and $63 \%$ had access to a lipid specialist which varied by their location (36\% urban, 30\% suburban, and 13\% rural). The

Received October 11, 2019

Revised October 24, 2019

Accepted December 12, 2019

Published online January 16, 2020 answers to the survey questions are provided in Table 1 and Figure 1.

\section{DISCUSSION}

Although most of our survey respondents manage patients with LDL-cholesterol levels diagnostic of HoFH, less than half did not recognize the diagnosis of $\mathrm{HoFH}$ in their patients and had difficulty in distinguishing HoFH from heterozygous familial hypercholesterolemia. This distinction is critical since patients with $\mathrm{HoFH}$ are at much higher risk of early and aggressive cardiovascular disease and warrant more intensive therapies. Historically, HoFH was diagnosed at LDLcholesterol levels $>500 \mathrm{mg} / \mathrm{dL}$; however, almost half of genetically proven homozygotes have untreated LDL-C levels $<$ $500 \mathrm{mg} / \mathrm{dL}^{2}{ }^{2}$ These findings do not appear to have made it into general practice.

When assessing cardiovascular risk in a patient with $\mathrm{HoFH}$, most clinicians would use a risk calculator. It is important to note that past and current cholesterol guidelines do not recommend using risk calculators in patients with $\mathrm{HoFH}$ and recommend treatment with high-intensity statins as soon as the clinical diagnosis is made. ${ }^{1}$ Most clinicians in our survey would prescribe high-intensity statins to treat HoFH patients. However, diet and exercise were chosen by many respondents as their first and second choices of therapy. They are important parts of the treatment of HoFH patients but have a relatively small effect. Only $24 \%$ of clinicians would start a male patient at age $<18$ and only $20 \%$ a female patient at age $<18$ on LDLcholesterol lowering medication. Because the presence of severely elevated LDL-C from birth confers such a high risk of premature atherosclerosis, current guidelines for $\mathrm{HoFH}$ suggest starting medication at the time of diagnosis and several statins are approved for treating HoFH from age $10 .{ }^{1}$

In our survey, less than $2 / 3$ of clinicians would use PCSK 9 inhibitors and only $7 \%$ would use lomitapide in patients with $\mathrm{HoFH}$, despite these drugs being approved to treat HoFH. Many would use fish oil or a fibrate which have little effect on LDL-cholesterol. About 2/3 of clinicians in our survey have access to a lipid specialist, but only $29 \%$ have access to 
Table 1 Answers to the Survey Questions

Survey question

Do you have patients with an untreated LDL-C $>$ or equal to $400 \mathrm{mg} / \mathrm{dL}$ ?

Answer

Do you have patients with a treated LDL-C > $300 \mathrm{mg} / \mathrm{dL}$ ?

What is your diagnosis for a patient with an untreated LDL-C > or equal to $400 \mathrm{mg} / \mathrm{dL}$ ?

No

Yes

No

$\mathrm{HoFH}$

$\mathrm{HeFH}$

Mixed hyperlipidemia

Familial Chylomicronemia

High cholesterol due to poor lifestyle habits

$\mathrm{HoFH}$

What is your diagnosis for a patient with a treated LDL-C > $300 \mathrm{mg} / \mathrm{dL}$ ?

$\mathrm{HeFH}$

Mixed hyperlipidemia

Familial Chylomicronemia

High cholesterol due to poor lifestyle habits

Genetic testing

What method do you use to diagnose HoFH?

Clinical criteria

Does your practice have access to a lipid specialist?

Yes

No

Yes

Does your practice have access to an LDL-apheresis center?

In a patient with $\mathrm{HoFH}$ what risk factors would you use to determine ASCVD risk?

No

Level of LDL-C

Level on non-HDL-C

Coronary artery calcium scoring

Level of $\mathrm{Lp}(\mathrm{a})$

Family history

Would you use a risk calculator to determine high risk for ASCVD in a patient with HoFH? Yes

No

What would you use to treat a patient with $\mathrm{HoFH}$ ?

High dose statin

Diet and exercise

PCSK9 inhibitor

Ezetimibe

Fish oil

Fibrate

Bile acid sequestrant

Niacin

LDL-apheresis

Low to moderate dose statin

Plant sterols

Lomitapide

$<18$ (years old)

$>18$

$<18$ (years old)

$>18$

LDL-C decrease by at least $50 \%$

LDL-C $<70 \mathrm{mg} / \mathrm{dL}$

LDL-C $<100 \mathrm{mg} / \mathrm{dL}$

ASCVD, atherosclerotic cardiovascular disease; HeFH, heterozygous familial hypercholesterolemia; HoFH, homozygous familial hypercholesterolemia; Lp(a), lipoprotein (a); $L D L-C$, low-density lipoprotein cholesterol; non-HDL-C, non-high-density lipoprotein cholesterol; PCSK9, proprotein convertase subtilisin/kexin type 9

an LDL apheresis center. Often patients with HoFH are difficult to treat and the lack of access to a lipid specialist and an apheresis center is a significant limitation to adequately treating patients with $\mathrm{HoFH}$.

In conclusion, most primary care clinicians do not adequately recognize or treat $\mathrm{HoFH}$, and do not have easy access to a lipid specialist or an apheresis center. Clinicians should suspect $\mathrm{HoFH}$ in any patient with a family history of high cholesterol or premature CV disease whose untreated LDLcholesterol is $\geq 400 \mathrm{mg} / \mathrm{dL}$ or whose treated level is $>300 \mathrm{mg} /$ $\mathrm{dL}$. Recent studies suggest that quick search terms in an electronic health record may improve the recognition of $\mathrm{HoFH}$ in clinical practice. ${ }^{3}$ There is a need for more education for primary care clinicians in recognizing and treating $\mathrm{HoFH}$, and for greater access to lipid specialists and LDL-apheresis centers.
Acknowledgments: We would like to acknowledge Vivian Grifantini and Amina Resheidat for their help in developing the survey and manuscript.

Corresponding Author: Dean G. Karalis, MD, FACC, FNLA; Thomas Jefferson University Hospital, 227 North Broad Street, Suite 200, Philadelphia, PA, USA (e-mail: dean.karalis@jefferson.edu).

Authors' Contribution All authors had access to the data and a role in writing the manuscript.

Funding Information The study was funded by an education grant from Aegerion Pharmaceuticals and Regenxbio.

\section{Compliance with Ethical Standards:}

Conflict of Interest: The authors declare that they do not have a conflict of interest. 


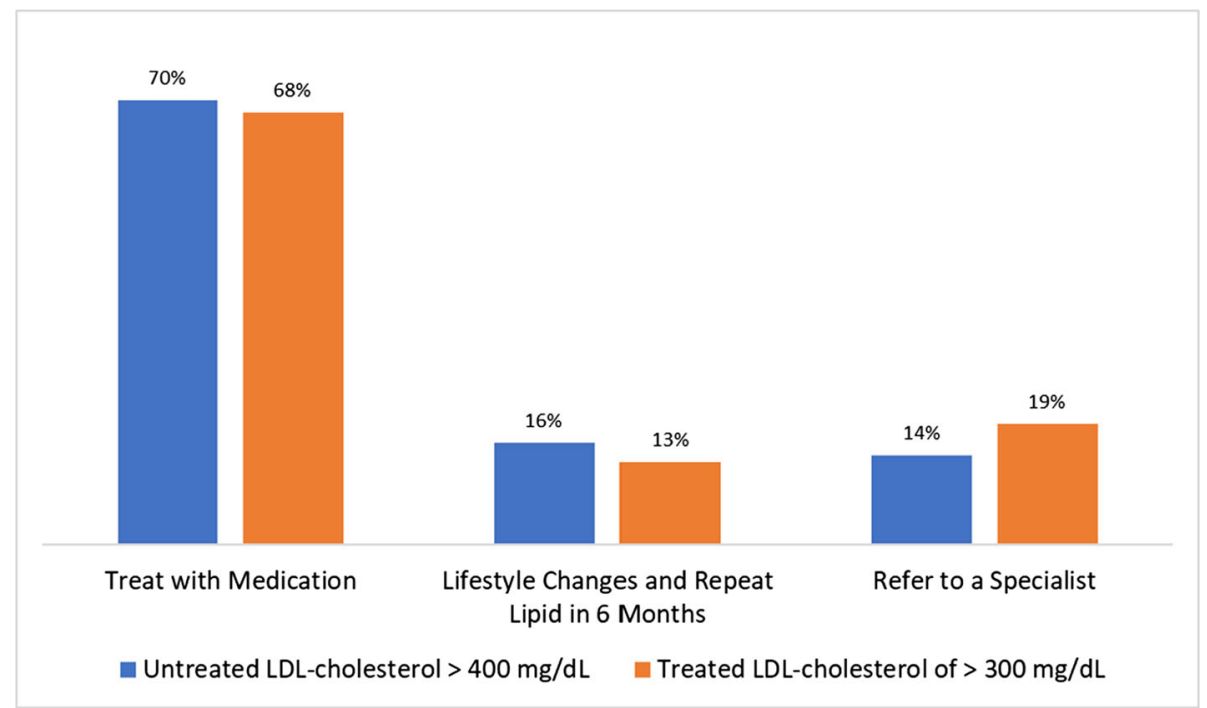

Figure 1 Initial choices for what steps the survey respondents would take in treating patients with an untreated LDL-cholesterol $\geq 400 \mathrm{mg} / \mathrm{dL}$ and for patients with a treated LDL-cholesterol $>300 \mathrm{mg} / \mathrm{dL}$.

Open Access This article is licensed under a Creative Commons Attribution 4.0 International License, which permits use, sharing, adaptation, distribution and reproduction in any medium or format, as long as you give appropriate credit to the original author(s) and the source, provide a link to the Creative Commons licence, and indicate if changes were made. The images or other third party material in this article are included in the article's Creative Commons licence, unless indicated otherwise in a credit line to the material. If material is not included in the article's Creative Commons licence and your intended use is not permitted by statutory regulation or exceeds the permitted use, you will need to obtain permission directly from the copyright holder. To view a copy of this licence, visit http:// creativecommons.org/licenses/by/4.0/.

\section{REFERENCES}

1. Gidding SS, Champagne MA, de Ferranti SD, et al. The agenda for familial hypercholesterolemia. A Scientific Statement from the American Heart Association. Circulation 2015; 132: 2167-2192

2. Sjouke B, Kusters DM, Kindt I, et al. Homozygous autosomal dominant hypercholesterolemia in the Netherlands: prevalence, genotype-phenotype relationship, and clinical outcome. Eur Heart J 2015; 36: 560-565

3. Knickelbine T, Lui M, Garberich R, et al. Familial hypercholesterolemia in a large ambulatory population: statin use, optimal treatment, and identification for advanced medical therapies. J Clin Lipid 2016; 10: 11821187

Publisher's Note Springer Nature remains neutral with regard to jurisdictional claims in published maps and institutional affiliations. 